\title{
Social cognition in borderline personality disorder: evidence for disturbed recognition of the emotions, thoughts, and intentions of others
}

\author{
Sandra Preißler ${ }^{1 *}$, Isabel Dziobek ${ }^{2,3}$, Kathrin Ritter ${ }^{1}$, Hauke R. Heekeren ${ }^{2,3}$ and Stefan Roepke , 3* $^{\text {* }}$ \\ Department of Psychiatry, Campus Benjamin Franklin, Charité - University Medicine Berlin, Berlin, Germany \\ 2 Max-Planck-Institute for Human Development, Neurocognition of Decision Making Group, Berlin, Germany \\ ${ }^{3}$ Cluster of Excellence Languages of Emotion, Freie Universität Berlin, Berlin, Germany
}

Edited by:

Dominique J. F. de Quervain, University of Basel, Switzerland

\section{Reviewed by:}

Jenifer Bartz, Mount Sinai School of

Medicine, USA

Arnoud Arntz, University of Maastrich,

Netherlands

\section{*Correspondence:}

Sandra Preißler and Stefan Roepke,

Department of Psychiatry, Campus

Benjamin Franklin, Charité-

Universitätsmedizin Berlin, Eschenallee

3, D-14050 Berlin, Germany.

e-mail: preissler.sandra@googlemail.

com; stefan.roepke@charite.de
Disturbed relatedness is a core feature of borderline personality disorder (BPD), and impaired social cognition or deficits in "mentalization" are hypothesized to underlie this feature. To date, only weak empirical evidence argues for impairment in the recognition of emotions, thoughts, or intentions in BPD. Data from facial emotion recognition research indicate that these abilities are altered in BPD only if tasks are complex. The present study aims to assess social cognitive abilities in BPD. Sixty-four women with BPD and 38 healthy controls watched the "Movie for the Assessment of Social Cognition" (MASC), a newly developed film displaying social interactions, and asking for an assessment of the intentions, emotions, and thoughts of the characters. In addition, participants completed an established but less ecologically valid measure of social cognition ("Reading the Mind in the Eyes"; RME). In the RME task, BPD patients did not display impairment in social cognition compared to healthy controls. By contrast, on the more sensitive MASC, women with BPD showed significantly impaired abilities in social cognition compared to healthy controls in their recognition of emotions, thoughts, and intentions. Comorbid PTSD, intrusions, and sexual trauma negatively predicted social cognitive abilities on the more sensitive MASC. Thus, our results suggest impaired social cognitive abilities in BPD. Especially for comorbid PTSD, intrusive symptoms, and history of sexual trauma predicted poor outcomes on social cognition tasks.

Keywords: borderline personality disorder, MASC, PTSD, empathy, social cognition, theory of mind, mentalization, trauma

\section{INTRODUCTION}

Borderline personality disorder (BPD) is a severe mental disorder, affecting up to $5.9 \%$ of the general population (Grant et al., 2008). This disorder heavily impairs affected individuals in multiple domains (Skodol et al., 2005) and presents a major burden to public health systems (Soeteman et al., 2008).

Three symptom clusters have been identified in BPD, namely affective dysregulation, impulsivity (behavioral dysregulation), and disturbed relatedness (Sanislow et al., 2002).

Affective dysregulation and impulsivity have been the focus of empirical studies, and have been identified as phenotypic traits of BPD in longitudinal studies (Zanarini et al., 2005), behavioral experiments (Domes et al., 2009), and brain imaging studies (Domes et al., 2009).

By contrast, disturbed relatedness in BPD has only been analyzed in a limited number of studies to date (e.g., Skodol et al., 2005; Hill et al., 2008; King-Casas et al., 2008), although the relational style of BPD has been suggested to be the best discriminator for diagnosis (Gunderson, 2007).

A major challenge in studying social interaction is the development of empirical tests that are close to real-life conditions (ecologically valid) with consistent underlying theoretical constructs that are capable of capturing major aspects of deviant relatedness as described in BPD.
A study by Frank and Hoffman (1986) compared BPD patients with clinical controls using a shortened version of the profile of non-verbal sensitivity (PONS; DePaulo and Rosenthal, 1979), in which participants had to choose one of two alternative affective descriptions after watching a 10-min video containing depictions of different emotional situations, each portrayed by the same woman. Borderline patients scored higher than controls on this measure of non-verbal sensitivity. Ladisich and Feil (1988) measured how well a member of an interacting group could predict the self-rated feelings of the other group members. BPD patients achieved the highest scores compared to other patients; they actually achieved scores comparable to the participating psychiatrist. These early findings and clinical observations (Krohn, 1974; Carter and Rinsley, 1977) led to the descriptive term "borderline empathy."

On the other hand, research with projective material from the Thematic Apperception Test and other narratives (Westen, 1990, 1991a,b; Westen et al., 1990a,b,c,d; Nigg et al., 1992; Segal et al., 1992, 1993) has indicated that BPD patients are able to make complex intentional attributions of other people's actions although they express more malevolent representations of others compared to controls (Veen and Arntz, 2000). A study by Arntz and Veen (2001) even found evidence for less complexity in BPD patients' character descriptions after watching film sequences of emotional and non-emotional film sequences. 
Recent advances in conceptualizing (Frith and Frith, 2005) and measuring social cognition could provide the possibility for empirically assessing the basic principles of the clinically observed disturbed relatedness in BPD (Hill et al., 2008). The concept of social cognition highly overlaps with the constructs of "theory of mind" (Premack et al., 1978) and "mentalizing" (Frith and Frith, 2006), and describes the ability to infer another's thoughts, feelings, and intentions.

Fonagy et al. (1996) provided preliminary evidence that impaired social cognition, as assessed by the Adult Attachment Interview (de Haas et al., 1994), is linked to BPD symptomatology. Also, Harari et al. (2010) found cognitive empathy, assessed with the interpersonal reactivity index (IRI; Davis, 1983), and "theory of mind," assessed with the "Faux pas" task (Baron-Cohen et al., 1997), to be impaired in BPD patients compared to controls. Nevertheless, these results are not consistent, as Arntz et al. (2009) could not find a deficit in "theory of mind" capacities in BPD patients, assessed with the advanced "theory of mind" task (Happé, 1994). Whereas Fertuck et al. (2009) found even enhanced mental state discrimination in BPD patients compared to controls with the "Reading the Mind in the Eyes" task (BaronCohen et al., 2001). Nevertheless, Fertuck et al.'s (2009) deficits in social cognition are considered core features of the disorder (Fonagy and Bateman, 2008). Furthermore, a specific form of psychotherapy called mentalization-based therapy has been developed and proven effective for BPD treatment (Fonagy and Bateman, 2008).

Most other prior studies on social cognition in BPD have used mainly facial emotion recognition tasks (e.g., by using static images, such as Ekman faces or morphing pictures; Lynch et al., 2006; Domes et al., 2008). The results of these studies have not been entirely consistent; in some studies patients with BPD were able to correctly identify emotional facial expressions, at times even more accurately than healthy controls (Wagner and Linehan, 1999; Lynch et al., 2006). In one study, neutral facial expressions were interpreted more negatively (Wagner and Linehan, 1999). In another study, Domes et al. (2008) examined the ratings of pictures of faces displaying two basic emotions at the same time (i.e., a blend), morphing from one emotion to the other. BPD patients showed a bias toward the perception of anger (Domes et al., 2008).

However, when facial emotion recognition tasks imitate more complex situations [e.g., by setting time limits for recognizing emotions in faces (Dyck et al., 2009), or with additional prosodic information (Minzenberg et al., 2006)], patients with BPD show increased error rates. Thus, these findings indicate that BPD patients show impairments in social cognition only on tasks that are more ecologically valid.

Also, results from facial emotion recognition tasks show that intrusive symptoms and comorbid PTSD are negative predictors for emotion recognition abilities in BPD (Dyck et al., 2009). This finding is of special interest, as many patients with BPD have childhood histories of sexual and/or physical abuse (Zanarini et al., 2002). Furthermore, comorbid PTSD is frequent in this group, and predicts a poor long-term outcome of the disorder (Zanarini et al., 2006). Thus, in addition to high heritability of BPD (Torgersen et al., 2008), these results argue that environmental factors (e.g., trauma) contribute to disturbed social cognition in BPD. In summary, for the current study we expected PTSD to be a negative predictor of social cognition.
As mentioned, empirical studies of social interactions are limited by the use of ecologically valid assessment instruments. These instruments are widely lacking. Our group recently developed the "Movie for the Assessment of Social Cognition" (MASC; Dziobek et al., 2006), which is a film displaying social interactions among multiple characters. The MASC empirically assesses the participant's recognition of the intentions, emotions, and thoughts of the movie characters, and allows for the analysis of social cognition in a more complex and ecologically valid manner.

The aim of the present study was twofold: First, we aimed to assess facets of social cognition in patients with BPD compared to controls, and second, we aimed to evaluate the impact of BPD symptomatology, comorbidity, and history of traumatic events on social cognitive abilities.

\section{MATERIALS AND METHODS SUBJECTS}

Sixty-four women with the diagnosis of BPD according to DSM-IV (American Psychiatric Association, 2000), and 38 healthy, age and IQ matched female comparison subjects participated in the study. All patients were admitted to our inpatient treatment program for BPD at the Department of Psychiatry, Charité-Universitätsmedizin Berlin, Germany, during which they were consecutively recruited into the study. Prior to hospital admission, all of them were on a waiting list and none was admitted for acute care. Patients were not reimbursed for study participation. Healthy controls were recruited via media advertisements and reimbursed for participation. All data were assessed between December, 2006, and June, 2008.

Axis II diagnoses were confirmed or excluded in patients and controls, respectively, with the German version of the Structured Clinical Interview for DSM-IV (SCID II; First et al., 1997), and Axis I diagnoses were assessed with the German version of the Mini International Neuropsychiatric Interview (M.I.N.I.; Sheehan et al., 1998). Fluid IQ was assessed with subtest 4 of the "Leistungsprüfsystem" (Horn, 1983), a standard German intelligence test. This test shows high validity and a good reliability (retest reliability $=0.77)$. On subtest 4 , participants have to recognize regularities and irregularities in series of numbers and letters; thus, only minimal education in terms of basic knowledge of numbers and letters is needed. In the standard procedure of the test, as applied in this study, IQ values are adapted for age. The study was approved by the ethics committee of the Charité Universitätsmedizin Berlin. All participants provided written informed consent after having received a thorough explanation of the study.

Exclusion criteria for the patients consisted of mental retardation, schizophrenia, and age younger than 18 years. Sociodemographic and clinical parameters of patients and controls are presented in Table 1. Later, patients were divided into two groups, one with and one without comorbid PTSD. These three groups (controls and two patient groups) were not statistically significantly different in age and fluid IQ (age: controls: mean $=31.66, \mathrm{SD}=10.27$; patients with PTSD: mean $=29.36, \mathrm{SD}=8.27$; patients without PTSD: mean $=29.05, \mathrm{SD}=9.26 ; F(2,99)=0.83, p=0.440$; IQ: controls: mean $=120.11, \mathrm{SD}=10.27$; patients with PTSD: mean $=115.57$, $\mathrm{SD}=9.64$; patients without PTSD: mean $=117.47, \mathrm{SD}=11.59$; $F(2,94)=1.30, p=0.275)$. 
Table 1 | Sociodemographic and clinical variables of women with borderline personality disorder and healthy comparison subjects.

\begin{tabular}{|c|c|c|c|c|c|c|}
\hline & \multicolumn{2}{|c|}{$\begin{array}{l}\text { Patients with } \\
\text { borderline } \\
\text { personality } \\
\text { disorder } \\
(N=64)\end{array}$} & \multicolumn{2}{|c|}{$\begin{array}{c}\text { Healthy } \\
\text { comparison } \\
\text { subjects } \\
(N=38)\end{array}$} & \multirow[b]{2}{*}{$\boldsymbol{t}$} & \multirow[b]{2}{*}{$\eta^{2}$} \\
\hline & Mean & SD & Mean & SD & & \\
\hline Age (years) & 29.2 & 8.9 & 31.7 & 10.3 & -1.29 & 0.017 \\
\hline Fluid intelligence ${ }^{a}$ & 116.7 & 10.9 & 120.1 & 10.3 & -1.49 & 0.023 \\
\hline MDE & $N$ & $\%$ & & & & \\
\hline Lifetime & 27 & 42.2 & & & & \\
\hline Current & 8 & 12.5 & & & & \\
\hline Current dysthymia & 22 & 34.4 & & & & \\
\hline $\begin{array}{l}\text { Substance use disorder } \\
\text { (last } 12 \text { month) }\end{array}$ & 12 & 18.8 & & & & \\
\hline Any anxiety disorder & 37 & 57.8 & & & & \\
\hline Current PTSD & 23 & 35.9 & & & & \\
\hline Any eating disorder & 16 & 25 & & & & \\
\hline Any cluster A PD & 6 & 9.4 & & & & \\
\hline Any other Cluster B PD & 7 & 10.9 & & & & \\
\hline Any cluster C PD & 27 & 42.2 & & & & \\
\hline \multicolumn{7}{|l|}{ No psychotropic } \\
\hline medication & 43 & 67.2 & & & & \\
\hline \multicolumn{7}{|l|}{ Current medication } \\
\hline Antidepressants & 20 & 31.2 & & & & \\
\hline Atypical antipsychotics & 7 & 10.9 & & & & \\
\hline
\end{tabular}

PTSD, posttraumatic stress disorder; SD, standard deviation; $P D$, personality disorder.

"Measured by subtest 4 of the "Leistungsprüfsystem" (Horn, 1983).

\section{“READING THE MIND IN THE EYES" TASK}

The revised version of the "Reading the Mind in the Eyes" task (RME; Baron-Cohen et al., 2001) involves inferring the mental state of a person solely from information conveyed by photographs of that person's eyes. The RME includes 40 items. Participants were asked to pick, for each pair of eyes, one out of four mental state descriptors (e.g., interested, hostile), where the descriptors varied for each item. The test is scored by adding up the number of mental state attributions correctly identified. The RME had an acceptable internal consistency in our dataset (Cronbach's $\alpha=0.71$ ).

\section{MOVIE FOR THE ASSESSMENT OF SOCIAL COGNITION}

The "Movie for the Assessment of Social Cognition" (MASC; Dziobek et al., 2006) requires subjects to attribute mental states to movie characters in an everyday life-relevant context. The MASC involves watching a 15 min movie about four persons spending an evening together having dinner. Dominant topics in the movie consist of dating and friendship issues. The film is paused at 45 points, and questions concerning the characters' feelings, thoughts, and intentions are asked (e.g., "What is Betty feeling?," "What is Cliff thinking?," "Why is Michael doing this?"). In detail, the MASC considers 15 items demanding the interpretation of emotions, 14 items for intentions, and 4 items for measuring thoughts.

The MASC has high interrater reliability $(\mathrm{ICC}=0.99)$, and high test-retest reliability ( $r=0.97$; Dziobek et al., 2006). In the present sample, the MASC total scale shows high internal consistency (Cronbach's $\alpha=0.86$ ). The internal consistency of the MASC subscale is fairly good (MASC emotions: Cronbach's $\alpha=0.62$; MASC thoughts: Cronbach's $\alpha=0.55$; MASC intentions: Cronbach's $\alpha=0.71)$. In the original validation study of the task using individuals on the autism spectrum, a population with possibly selective problems in social cognition, high correlations of the MASC score with social functioning have been found (Dziobek et al., 2006). Each correct response is scored as one point and responses are added together to form a total score. In addition, the MASC allows for a separate quantification of the extent to which emotional mental states, thoughts, and intentions are inferred correctly. In our sample, no correlation between the fluid IQ measure and the MASC sum score was found $(r=0.096, p=0.356)$.

\section{BORDERLINE SYMPTOM LIST}

The "Borderline Symptom List" (BSL) is a dimensional self-report measure specifically developed to quantify borderline symptomatology (Bohus et al., 2007). The scale achieved high internal consistency (Cronbach's $\alpha=0.97$ for the sum score), test-retest reliability ( $r=0.84$ for the total scale), and validity (scale intercorrelations ranged from 0.21 to 0.68 ; Bohus et al., 2007). The BSL-95 contains a list of 95 subjective complaints and impairments often reported by patients with BPD. These BSL items are based on criteria from the DSM-IV (American Psychiatric Association, 2000), the revised version of the Diagnostic Interview for BPD (Gunderson et al., 1981), and the opinions of both clinical experts and patients with BPD. The questionnaire uses a Likert-type rating format $(0=$ "not at all," 1 = "a little," 2 = "rather," 3 = "much," and 4 = "very strong"), asking the patient to evaluate their symptoms during the past week. Factor analyses revealed seven factors: self-image, affect regulation, auto aggression, dysthymia, social isolation, intrusions, and hostility. The "intrusions" subscale of the BSL reflects PTSD symptomatology and entails items such as: "I could hardly control my memories," "I was tortured by images," and "I suffered from nightmares." A total score and subscores for the seven factors can be computed.

\section{POSTTRAUMATIC STRESS DIAGNOSTIC SCALE}

To measure traumatic experiences as well as to indicate the severity of the comorbid posttraumatic stress disorder, we used the "Posttraumatic Stress Diagnostic Scale" (PDS; Foa, 1995). The PDS is a self-report measure in which the patient is asked to indicate which of a list of traumatic experiences she or he or somebody else underwent in the past. The questionnaire is designed to aid in the detection and diagnosis of PTSD. It parallels DSM-IV (American Psychiatric Association, 2000) diagnostic criteria for a PTSD diagnosis.

\section{STATISTICAL ANALYSIS}

For sufficient power $(80 \%)$ of the study, a sample size of $n=968$ would be required to detect small effect sizes $(f=0.10)$. For large effect sizes $(f=0.40)$, a sample size of 64 would be needed, and for medium effect sizes $(f=0.25)$, a sample size of 158 would 
be necessary (Erdfelder et al., 1996). All further analyses were conducted with SPSS, version 15.0 (SPSS, Chicago). Before use of parametric tests, histograms and Kolmogorov-Smirnov tests were performed to demonstrate normality of variable distributions. Between-groups comparisons were done with univariate analysis of variance (ANOVA). Further analysis was performed with multiple analyses of variance (MANOVA). In an exploratory analysis, IQ was added as a covariate in an ANCOVA model for the two (patients with BPD and healthy controls) and the three groups (BPD patients with PTSD, BPD patients without PTSD, and healthy controls), which revealed no significant influence of IQ for either analysis $(p>0.50)$ and thus, this covariate was excluded from the analyses. Furthermore, we carried out a multiple stepwise regression analysis to derive the best multivariate equation between a dependent (e.g., measure for social cognition) and multiple independent parameters (e.g., comorbidity, psychopathological symptoms, history of trauma). All significance levels were set to 0.05 (two tailed). All values are given as means and standard deviations (SD) when appropriate.

\section{RESULTS}

\section{SOCIAL COGNITION IN BPD}

To assess differences between patients with BPD and controls in RME, we performed an ANOVA $(F(1,93)=0.30, p=0.588)$, which did not reveal any group differences (Table 2 ).

Further, differences between patients with BPD and healthy controls on the MASC were calculated with an ANOVA model for the MASC total score $(F(1,102)=17.56, p<0.001)$. The analysis revealed significantly lower scores for patients with BPD (Table 2).

Table 2 | Group comparison between patients with borderline personality disorder and controls in the "Reading the Mind in the Eyes" test and the "Movie for the Assessment of Social Cognition" (MASC).

\begin{tabular}{|c|c|c|c|c|c|c|}
\hline & \multicolumn{2}{|c|}{$\begin{array}{l}\text { Patients with } \\
\text { borderline } \\
\text { personality } \\
\text { disorder } \\
(N=64)\end{array}$} & \multicolumn{2}{|c|}{$\begin{array}{c}\text { Healthy } \\
\text { comparison } \\
\text { subjects } \\
(N=38)\end{array}$} & \multirow[b]{2}{*}{$F^{\mathrm{a}}$} & \multirow[b]{2}{*}{$\eta^{2}$} \\
\hline & Mean & SD & Mean & SD & & \\
\hline $\begin{array}{l}\text { "Reading the mind } \\
\text { in the eyes" } \\
\text { sum score }\end{array}$ & 24.3 & 5.6 & 24.9 & 3.5 & 0.30 & 0.00 \\
\hline MASC sum score & 29.9 & 7.8 & 35.6 & 3.9 & $17.6^{* *}$ & 0.15 \\
\hline $\begin{array}{l}\text { MASC subscore } \\
\text { emotion }\end{array}$ & 10.5 & 3.2 & 11.8 & 1.7 & $5.5^{*}$ & 0.05 \\
\hline $\begin{array}{l}\text { MASC subscore } \\
\text { thoughts }\end{array}$ & 3.1 & 0.9 & 3.5 & 0.6 & $6.1^{*}$ & 0.05 \\
\hline $\begin{array}{l}\text { MASC subscore } \\
\text { intentions }\end{array}$ & 8.9 & 2.8 & 11.0 & 1.9 & $16.6^{* *}$ & 0.14 \\
\hline
\end{tabular}

$S D$, standard deviation.

"ANOVA model for "Reading the mind in the eyes" comparison, ANOVA model for "MASC sum score" and MANOVA model for "MASC subscores," *p $<0.05$, ${ }^{*} p<0.01$.
For MASC subscore analyses, the MANOVA revealed significant differences between groups, Wilks-Lambda, $F(3,102)=5.78$, $p=0.001$. All MASC subscores were significantly lower for the BPD group, indicating significant impairments in inferring the emotions, thoughts, and intentions of other persons (Table 2).

\section{COMORBID PTSD AND INTRUSIVE SYMPTOMS}

To elucidate whether specific symptoms of BPD account for the deficits on the MASC scales, in a first step and for preliminary exploratory data analysis, four stepwise forward linear regression analyses within the BPD group were performed. The seven BSL subscales served as independent variables to predict the MASC total score or subscales. A significant model was identified only for the MASC subscale "thoughts" $\left(R^{2}=0.09, F=6.20, p=0.015\right)$, with the BSL subscale "intrusions" ( $\beta=-0.35, t=-2.50)$ as a significant predictor. All additional stepwise forward linear regression analyses with the MASC total score and the subscores "emotions" and "intentions" as dependent variables revealed no significant models.

For further preliminary and exploratory data analyses, and to investigate the influence of comorbid disorders (major depression, substance abuse, eating disorders, posttraumatic stress disorder, and other personality disorders) or psychotropic medication (antidepressants or atypical neuroleptics) on MASC performance, four additional stepwise forward linear regression analyses were performed within the BPD group. Again, only one significant model was found $\left(R^{2}=0.13, F=9.35, p=0.003\right)$, identifying PTSD $(\beta=-0.69, t=-3.06, p<0.05)$ as a significant factor influencing the ability to infer thoughts. No other stepwise forward linear regression analysis with the MASC total score and the subscales "emotions" and "intentions" as dependent variables yielded a significant model.

Thus, the preliminary and exploratory analyses revealed that comorbid PTSD and PTSD symptoms are associated with impairment in social cognition in BPD. For statistically more valid analyses of this impact, measures of social cognition were compared using an ANOVA model for the sum score and a MANOVA model for MASC subscores using Bonferroni-corrected post hoc comparisons between BPD patients with and without comorbid PTSD and control subjects (Table 3). Patients with BPD without comorbid PTSD displayed significant impairments only for the recognition of intentions compared to healthy controls (Table 3). By contrast, patients with BPD having comorbid PTSD displayed significant impairments on all three subscales: recognition of emotions, thoughts, and intentions, compared to healthy controls (Table 3 ). The threegroup comparison (ANOVA) for the RME sum score did not reveal significant group differences $(F(2,90)=0.28, p=0.756)$.

To guarantee that differences in social cognitive performance for the BPD groups with and without PTSD were not solely attributable to higher BPD symptom severity in the group with PTSD, BSL scores were compared between the two groups. An ANOVA revealed no significant difference between the two groups for the BSL total score: patients without PTSD: mean $=2.20, \mathrm{SD}=0.70$; patients with PTSD: mean $=2.40, \mathrm{SD}=0.70 ; F(1,64)=1.40 ; p=0.241$. Of all BSL subscales, only the scale "intrusions" differed between the two groups, as assessed by a MANOVA: patients without PTSD: mean $=1.1, \mathrm{SD}=0.7$; patients with PTSD: mean $=1.7, \mathrm{SD}=0.8$; $F(1,64)=8.60 ; p=0.005$. Also, inclusion of the BSL total score as 
Table 3 | Group comparison between patients with borderline personality disorder with and without comorbid PTSD and controls in the "movie for the assessment of social cognition" (MASC).

\begin{tabular}{|c|c|c|c|c|c|c|c|c|c|c|c|}
\hline & \multicolumn{2}{|c|}{$\begin{array}{l}\text { Patients with } \\
\text { BPD without } \\
\text { PTSD ( } N=42)\end{array}$} & \multicolumn{2}{|c|}{$\begin{array}{l}\text { Patients with } \\
\text { BPD with } \\
\text { PTSD ( } N=22)\end{array}$} & \multicolumn{2}{|c|}{$\begin{array}{c}\text { Healthy } \\
\text { comparison } \\
\text { subjects } \\
(N=38)\end{array}$} & \multirow[b]{2}{*}{$\boldsymbol{F}^{\mathrm{a}}$} & \multirow[b]{2}{*}{$\eta^{2}$} & \multicolumn{3}{|c|}{$\begin{array}{l}\text { Post hoc tests } \\
\text { (Bonferroni) }\end{array}$} \\
\hline & Mean & SD & Mean & SD & Mean & SD & & & 1 vs 2 & 1 vs 3 & 2 vs 3 \\
\hline MASC sum score & 31.3 & 6.8 & 27.2 & 9.1 & 35.6 & 3.9 & $12.1 * *$ & 0.20 & 0.053 & 0.012 & 0.000 \\
\hline MASC subscore thoughts & 3.3 & 0.7 & 2.6 & 1.1 & 3.5 & 0.6 & $9.4^{* *}$ & 0.16 & 0.002 & 0.998 & 0.000 \\
\hline MASC subscore intentions & 9.3 & 2.6 & 8.2 & 3.0 & 11.0 & 1.9 & $10.0^{* *}$ & 0.17 & 0.256 & 0.009 & 0.000 \\
\hline
\end{tabular}

PTSD, posttraumatic stress disorder; SD, standard deviation.

"ANOVA model for "MASC sum score" and MANOVA model for "MASC subscores," * $p<0.05,{ }^{* *} p<0.01$.

a covariate in the model with two groups (BPD patients with and without PTSD) for the MASC total score (ANCOVA) and the three MASC subscores (MANCOVA) revealed no significant influence of the covariate (ANCOVA: $p=0.552$; MANCOVA: $p=0.785$ ).

\section{INFLUENCE OF TRAUMATIC EVENTS}

Development of PTSD presumes the experiencing or witnessing of traumatic events. Using the PDS scale, 31 patients with BPD (48.4\%) reported experiencing a history of "accident or fire," $26(40.6 \%)$ reported "non-sexual assault (unknown assailant)," $45(70.3 \%)$ reported "non-sexual assault (known assailant)," 36 (56.3\%) reported "sexual assault (unknown assailant)," and 37 (57.8\%) reported "sexual assault (known assailant)." No sexual assault by a known assailant was reported in the control group. To assess which traumatic events have predictive value for impairments in social cognition in BPD patients, a forward stepwise linear regression with the MASC total score as dependent variable and reported trauma as independent variable was performed. Sexual assault from a known assailant $(\beta=-4.61, t=-2.41, p=0.019)$ was predictive of impairments on the MASC $\left(R^{2}=0.086, F=5.82\right)$. Also, the ANOVA model with the three-group comparison (BPD with and without reported sexual assault from a known assailant and controls) revealed a significant influence of group $(F(2$, $102)=13.39, p<0.001)$. Post hoc $t$-tests (Bonferroni corrected) indicated significantly lower MASC total scores for patients with sexual assault compared to patients without sexual assault $(p=0.017)$ and compared to controls $(p<0.001)$. Seventeen patients with BPD with comorbid PTSD (45.9\%) and 20 patients with BPD without comorbid PTSD (54.1\%) reported "sexual assault (known assailant)," indicating an independent risk factor in addition to comorbid PTSD for impaired social cognition.

Additionally, to guarantee that differences in social cognitive performance in the BPD groups with and without "sexual assault (known assailant)" were not solely attributable to higher BPD symptom severity in the group with a history of abuse, BSL scores were compared between the two groups. An ANOVA revealed no significant difference between the two groups for the BSL total score: patients without "sexual assault (known assailant)": mean $=2.2, \mathrm{SD}=0.7$; patients with "sexual assault (known assailant)": mean $=2.4, \mathrm{SD}=0.6 ; F(1,64)=1.65 ; p=0.204$.

\section{DISCUSSION}

The present study comprises a systematic empirical assessment of social cognition in patients with BPD using a more ecologically valid instrument. Whereas the RME task failed to detect significant impairments in social cognition in patients with BPD, the more ecologically valid MASC clearly identified significant impairments. Patients with BPD were impaired in the recognition of the feelings, thoughts, and intentions of the starring movie characters. Thus, our results support evidence from former studies (Fonagy et al., 1996; Harari et al., 2010) and are in contrast to findings of unimpaired or enhanced social cognition abilities (e.g., Arntz et al., 2009; Fertuck et al., 2009).

The result of preserved performance on the RME task in BPD is in line with previous findings reporting no deficits in facial emotion recognition for simple tasks with no time limits or additional confounding variables (Domes et al., 2009). However, these findings stand in contrast to the finding of Fertuck et al. (2009), who reported enhanced RME performance in BPD. In the Fertuck et al. (2009) study, significantly more men were included in the control group. Men are reported to be less accurate, as well as less sensitive in labeling facial expressions (Montagne et al., 2005). Also, controls from that study performed at the lower end of the range when compared to controls from other studies using the RME task (Fertuck et al., 2009). Further, a higher percentage of NonCaucasian participants were in the control group, whereas in the BPD group most participants were Caucasian and the RME tasks displays eye-regions of Caucasians (Fertuck et al., 2009). Our results also contradict the findings of Arntz et al. (2009) who found that borderline patients had no significant impairment in a "theory of mind" task based on completion of mental stories (Happé, 1994), compared to Cluster $\mathrm{C}$ patients and controls. In contrast to the advanced "theory of mind" task (Happé, 1994) applied by Arntz et al. (2009), we used the more complex and ecologically valid film material presented by the MASC. In this task, patients with BPD displayed significant impairments. These results are in line with former studies of emotion recognition, indicating that patients with BPD show deficits in the fast discrimination of negative and neutral facial expressions (Dyck et al., 2009). In addition, complex tasks for assessing emotion recognition with integrated facial and prosodic stimuli revealed impairments for patients with BPD (Minzenberg 
et al., 2006). The results of impaired social cognition measured by the MASC, especially in the recognition of intentions, are in line with a previous study showing that mental state reasoning capacities are compromised in BPD (Fonagy and Bateman, 2006).

In summary, our results support the notion that higher-order integration of social information within a limited time frame is impaired in patients with BPD. Further, we extended these findings of impaired emotion recognition to thoughts and intentions, which seem to be even more impaired in BPD.

The present findings of impaired social cognition can explain several clinical symptoms of BPD. Deficits in correctly identifying the emotions, thoughts, and intentions occurring in social situations could result in fear of abandonment, alternating between extremes of idealization and devaluation of other persons, and subsequent suicidal gestures or threats. Further studies are needed to assess the cognitive and behavioral impacts of impaired social cognition in BPD.

In the present study our preliminary analyses identified three factors contributing to impaired social cognition in BPD: intrusive symptoms, comorbid PTSD, and sexual assault by a known assailant. Intrusiveness as measured by the BSL in the patient group negatively predicted outcomes on the MASC, especially for recognition of thoughts. Also, comorbid PTSD was associated with impairment in social cognition in $\mathrm{BPD}$, especially for recognition of thoughts and intentions. Intrusions are core symptoms of PTSD; thus, both results argue for a negative impact of PTSD on social cognition. PTSD has been described as associated with low IQ and executive function deficits (e.g., Gilbertson et al., 2006). Both could contribute to findings of impaired social cognition in BPD patients with comorbid PTSD. Although influence of fluid IQ on social cognition was not significant in our data, further studies are needed to address this topic. Also, suppression of intrusive thoughts, which has been shown to have a negative impact on working memory (Brewin and Smart, 2005), could thereby have a negative impact on attention and thus contribute to impaired social cognition task performance in patients with comorbid PTSD. Thus, our results are in line with and extend previous findings of evidence for disturbed processing of negative or threatening visual information, as well as deviant neural responses to negative facial emotion expression in patients with PTSD (Shin et al., 2005).

Furthermore, our results provide preliminary evidence for the finding that sexual assault by a known assailant is associated with impaired social cognition. These findings are of special interest as adult BPD is associated with high rates of childhood maltreatment (Zanarini, 2000a,b). Patients with BPD report more types of abuse in childhood, beginning earlier in life, and repeated over longer periods of time than for comparison groups (Zanarini et al., 1997). As $54.1 \%$ of patients with BPD without comorbid PTSD reported sexual assault by a known assailant, this trauma with comorbid PTSD seems to be a partially independent risk factor. Nevertheless, trauma type assessment was based on the self-reported PDS scale. Thus, further studies are needed to assess more precisely the impact of trauma and trauma type on social cognition in BPD. In previous studies, severity of borderline pathology correlated with severity of childhood abuse, especially sexual abuse (Silk et al., 1995). In the present study, patients with BPD with and without PTSD, and with and without a history of sexual abuse did not significantly differ in severity of BPD symptoms. Thus, in our sample, severity of BPD did not significantly account for the finding of more impaired social cognition in comorbid PTSD or for patients with a history of sexual abuse.

Referring to the concept of the gene-environment interaction as a contributing factor to the development of psychiatric disorders, one could speculate about the genetic origins of the deficits in social cognition, as BPD has high heritability (Torgersen et al., 2008). However, our results argue for at least an additional environmental component, given that intrusions, PTSD, and sexual abuse point to the presence of environmental strains.

Interestingly, emotion dysregulation as a core feature of BPD (Sanislow et al., 2002), as assessed using the BSL, did not significantly account for impaired social cognition in our analysis within the BPD group, possibly indicating impaired social cognition as part of an independent factor of disturbed relatedness within BPD.

The findings of intrusive symptoms, comorbid PTSD, and a history of sexual abuse as predictors for impaired social cognition can be interpreted within the actual knowledge of the neural basis of social cognition.

In the present study, emotion recognition in $\mathrm{BPD}$, as measured by the MASC, was less prominently impaired than recognition of intentions in the total BPD sample compared to controls. Simulation theory proposes that we can understand the mental states of others on the basis of our own mental state (Gallese and Goldman, 1998). Through recognizing the facial expression of another person we infer that person's emotional state and attribute the emotion to the encounter. This process seems to be more basal, referring less to higher cognitive functions, and is less prone to learned knowledge about social interactions (Frith and Frith, 2006). The finding of less impaired emotion recognition as compared to the recognition of intentions for the present MASC task for BPD patients indicates less impairment in this more basal social cognitive process.

Experiential learning is crucial for our ability to recognize the thoughts and intentions of others in social encounters. The temporal pole, the medial prefrontal cortex, and the adjacent paracingulate cortex seem to be involved in that process (Damasio et al., 2004). Thus, more prominent impairment in the recognition of intentions and, for patients with intrusions and comorbid PTSD, more impairment in the recognition of thoughts and intentions, may indicate that environmental factors like trauma influence these learning-dependent capacities, which might be related to deficits in the frontal lobe. Imaging data support the notion of frontal brain dysfunction in patients with BPD (Schmahl and Bremner, 2006), with possible additional impairment of frontal neural networks in BPD patients with comorbid PTSD (Driessen et al., 2004). Also, our finding of history of sexual assault by a known assailant as a predictor for impaired social cognition could represent an indicator of an invalidating environment where adequate social learning was hindered for the child while growing up.

Our study has several limitations. The results do not imply that a deficit in social cognition is specific to BPD. By contrast, such deficits have been described in a number of psychiatric disorders (e.g., euthymic bipolar patients, Montag et al., 2010; Asperger individuals, Dziobek et al., 2006). Thus, concluding from our results, follow-up studies are needed to assess social cognition abilities in PTSD patients after mono-trauma or chronic 
traumatization and in individuals without PTSD after trauma, especially after sexual traumatization, to further explore our findings. Additionally, the sample size of $n=102$ was capable of detecting only large effects with a power of 0.80 . Finally, results were restricted to women with BPD.

Our data have several clinical implications. Deficits in social cognition in patients with BPD, especially with comorbid PTSD, should be considered in psychotherapy. Also, a history of sexual abuse as a predictor for impaired social cognition should be taken into account. Presumed emotions, thoughts, and intentions of interaction partners are often triggers of dysfunctional behavior in BPD. Thus, a reanalysis of these social triggers should be included in psychotherapy. Also, the emotions and cognitions of the therapist him- or herself should not be assumed to be accurately understood by the patient, but rather should be explicitly expressed. Moreover, psychotherapeutic strategies and trainings for enhancing social cognitive abilities should be integrated into the treatment of this patient

\section{REFERENCES}

American Psychiatric Association. (2000). Diagnostic and Statistical Manual of Mental Disorders: DSM$I V$-TR. Washington, DC: American Psychiatric Association.

Arntz,A., Bernstein, D., Oorschot, M., and Schobre, P. (2009). Theory of mind in borderline and cluster-C personality disorder. J. Nerv. Ment. Dis. 197, 801-807.

Arntz,A., and Veen, G. (2001). Evaluations of others by borderline patients. $J$. Nerv. Ment. Dis. 189, 513-521.

Baron-Cohen, S., Jolliffe, T., Mortimore, C., and Robertson, M. (1997). Another advanced test of theory of mind: evidence from very high functioning adults with autism or Asperger syndrome. J. Child Psychol. Psychiatry 38, 813-822.

Baron-Cohen, S., Wheelwright, S., Hill, J., Raste, Y., and Plumb, I. (2001). The "reading the mind in the eyes" test revised version: a study with normal adults, and adults with Asperger syndrome or high-functioning autism. J. Child Psychol. Psychiatry 42, 241-251.

Bohus, M., Limberger, M. F., Frank, U., Chapman, A. L., Kuhler, T., and Stieglitz, R. D. (2007). Psychometric properties of the Borderline symptom list (BSL). Psychopathology 40, 126-132.

Brewin, C. R., and Smart, L. (2005). Working memory capacity and suppression of intrusive thoughts. J. Behav. Ther. Exp. Psychiatry. 36, 61-68.

Carter, L., and Rinsley, D. B. (1977). Vicissitudes of empathy in a borderline adolescent. Int. J. Psychoanal 4, 317-326.

Damasio, H., Tranel, D., Grabowski, T., Adolphs, R., and Damasio, A. (2004). Neural systems behind word and concept retrieval. Cognition 92, 179-229.

Davis, M.H.(1983). Measuring individual differences in empathy: evidence for a multidimensional approach. J. Pers. Soc. Psychol. 44, 14.

de Groot, E. R., Verheul, R., and Trijsburg, R. W. (2008). An integrative perspective on psychotherapeutic treatments for borderline personality disorder. $J$. Pers. Disord. 22, 332-352.

de Haas, M. A., Bakermans-Kranenburg, M.)., and van Ijzendoorn, M.H.(1994). The adult attachment interview and questionnaires for attachment style, temperament, and memories of parental behavior. J. Genet. Psychol. 155, 471-486.

DePaulo, B. M., and Rosenthal, R. (1979). The structure of nonverbal decoding skills. J. Pers. 47, 506-517.

Domes, G., Czieschnek, D., Weidler, F., Berger, C., Fast, K., and Herpertz, S. C. (2008). Recognition of facial affect in borderline personality disorder. $J$. Pers. Disord. 22, 135-147.

Domes, G., Schulze, L., and Herpertz, S. C. (2009). Emotion recognition in borderline personality disorder-a review of the literature. J. Pers. Disord. 23, 6-19.

Driessen, M., Beblo, T., Mertens, M., Piefke, M., Rullkoetter, N., Silva-Saavedra, A., Reddemann, L., Rau, H., Markowitsch, H. J., Wulff, H., Lange, W., and Woermann, F. G. (2004). Posttraumatic stress disorder and $\mathrm{AMRI}$ activation patterns of traumatic memory in patients with borderline personality disorder. Biol. Psychiatry 55, 603-611.

Dyck, M., Habel, U., Slodczyk, J., Schlummer, J., Backes, V., Schneider, F., and Reske, M. (2009). Negative bias in fast emotion discrimination in borderline personality disorder. Psychol. Med. 39, 855-864.

group, with special respect to PTSD and traumatic experiences. Although different psychotherapeutic programs such as Dialectic Behavior Therapy, Transference Focused Psychotherapy, Schema Focused Therapy, Supportive Psychotherapy, and MentalizationBased Therapy, which all address social cognition in their own ways, have proven effective in the treatment of BPD (de Groot et al., 2008), information on their capacities to improve social cognition is still lacking.

In summary, the present study provides additional valuable empirical evidence for impaired social cognition in patients with BPD. In particular, PTSD symptoms and sexual trauma caused by a family member or acquaintance predict poor outcomes on social cognition tasks.

\section{ACKNOWLEDGMENTS}

This research was supported by a grant from the Federal Ministry of Education and Research, Germany (BMBF - 01GO0518).

Dziobek, I., Fleck, S., Kalbe, E., Rogers, K. Hassenstab, J., Brand, M., Kessler, J. Woike, J. K., Wolf, O. T., and Convit, A. (2006). Introducing MASC: a movie for the assessment of social cognition. J. Autism Dev. Disord. 36, 623-636.

Erdfelder, E., Faul, F., and Buchner, A. (1996). A general power analysis program. Behav. Res. Methods Instrum. Comput. 28, 1-11.

Fertuck, E. A., Jekal, A., Song, I., Wyman, B., Morris, M. C., Wilson, S. T., Brodsky, B. S., and Stanley, B. (2009). Enhanced "reading the mind in the eyes" in borderline personality disorder compared to healthy controls. Psychol. Med. 39, 1-10.

First, M. B., Spitzer, R. L., Smith, B. L., Gibbon, M., and Williams, J. B. W. (1997).Structured Clinical Interview for DSM-IV Axis II Personality Disorders (SCID-II). Arlington, VA: American Psychiatric Publishing, Inc.

Foa, E. B. (1995). Posttraumatic Stress Diagnostic Scale. Minneapolis, MN: NCS Pearson, Inc.

Fonagy, P., and Bateman, A. (2008). The development of borderline personality disorder-a mentalizing model. J. Pers. Disord. 22, 4-21.

Fonagy, P., and Bateman, A. W. (2006) Mechanisms of change in mentalization-based treatment of BPD. J. Clin. Psychol. 62, 411-430.

Fonagy, P., Leigh, T., Steele, M., Steele, H., Kennedy, R., Mattoon, G., Target, M., and Gerber, A. (1996). The relation of attachment status, psychiatric classification, and response to psychotherapy. J. Consult. Clin. Psychol. 64, 22-31.

Frank, H., and Hoffman, N. (1986). Borderline empathy: an empirical investigation. Compr. Psychiatry 27, 387-395.

Frith, C., and Frith, U. (2005). Theory of mind. Curr. Biol. 15, R644-R646.
Frith, C. D., and Frith, U. (2006). The neural basis of mentalizing. Neuron 50, 531-534.

Gallese, V., and Goldman, A. (1998). Mirror neurons and simulation theory of mind-reading. Trends Cogn. Sci. 2, 9.

Gilbertson, M.W., Paulus, L.A., Williston, S. K., Gurvits, T. V., Lasko, N. B., Pitman, R. K., and Orr, S. P. (2006). Neurocognitive function in monozygotic twins discordant for combat exposure: relationship to posttraumatic stress disorder. J. Abnorm. Psychol. 115, 484-495.

Grant, B. F., Chou, S. P., Goldstein, R. B., Huang, B., Stinson, F. S., Saha, T. D., Smith, S. M., Dawson, D.A., Pulay, A. J., Pickering, R. P., and Ruan, W. J. (2008). Prevalence, correlates, disability, and comorbidity of DSM-IV borderline personality disorder: results from the wave 2 national epidemiologic survey on alcohol and related conditions. $J$. Clin. Psychol. 69, 533-545.

Gunderson, J. G. (2007). Disturbed relationships as a phenotype for borderline personality disorder. Am. J. Psychiatry 164, 1637-1640.

Gunderson, J. G., Kolb, J. E., and Austin, V. (1981). The diagnostic interview for borderline patients. Am. J. Psychiatry 138, 896-903.

Happé, F. G. E. (1994). An advanced test of theory of mind: understanding of story characters' thoughts and feelings by able autistic, mentally handicapped, and normal children and adults. $J$. Autism Dev. Disord. 24, 129-154.

Harari,H., Shamay-Tsoory, S.G., Ravid,M., and Levkovitz, Y. (2010). Double dissociation between cognitive and affective empathy in borderline personality disorder. Psychiatry Res. 175, 277-279.

Hill, J., Pilkonis, P., Morse, J., Feske, U., Reynolds, S., Hope, H., Charest, C., 
and Broyden, N. (2008). Social domain dysfunction and disorganization in borderline personality disorder. Psychol. Med. 38, 135-146.

Horn, W. (1983). Leistungsprüfsystem, LPS. Göttingen: Hogrefe.

King-Casas, B., Sharp, C., Lomax-Bream, L., Lohrenz, T., Fonagy, P., and Montague, P. R. (2008). The rupture and repair of cooperation in borderline personality disorder. Science 321, 806-810.

Krohn, A. (1974). Borderline "empathy" and differentiation of object representations: a contribution to the psychology of object relations. Int. J. Psychoanal. Psychother. 3, 142-165.

Ladisich, W., and Feil, W. B. (1988). Empathy in psychiatric patients. $\mathrm{Br}$. J. Med. Psychol. 61 (Pt 2), 155-162.

Lynch, T. R., Rosenthal, M. Z., Kosson, D. S., Cheavens, J. S., Lejuez, C. W., and Blair, R. J. (2006). Heightened sensitivity to facial expressions of emotion in borderline personality disorder. Emotion 6, 647-655.

Minzenberg, M. J., Poole, J. H., and Vinogradov, S. (2006). Social-emotion recognition in borderline personality disorder. Compr. Psychiatry 47, 468-474.

Montag, C., Ehrlich, A., Neuhaus, K., Dziobek, I., Heekeren, H. R., Heinz, A., and Gallinat, J. (2010). Theory of mind impairments in euthymic bipolar patients. J. Affect. Disord. 123, 264-269.

Montagne, B., Kessels, R. P., Frigerio, E., de Haan, E. H., and Perrett, D. I. (2005). Sex differences in the perception of affective facial expressions: do men really lack emotional sensitivity? Cogn. Process 6, 136-141.

Nigg, J. T., Lohr, N. E., Western, D., Gold, L. J., and Silk, K. R. (1992). Malevolent object representations in borderline personality disorder and major depression. J. Abnorm. Psychol. 101, 61-67.

Premack, D., Woodruff, G., and Kennel, K. (1978). Paper-Marking test for chimpanzee: simple control for social cues. Science 202, 903-905.

Sanislow, C. A., Morey, L. C., Grilo, C. M., Gunderson, J. G., Shea, M. T., Skodol, A. E., Stout, R. L., Zanarini, M. C., and McGlashan, T. H. (2002). Confirmatory factor analysis of DSM-IV borderline, schizotypal, avoidant and obsessive-compulsive personality disorders: findings from the collaborative longitudinal personality disorders study. Acta Psychiatr. Scand. 105, 28-36.

Schmahl, C., and Bremner, J. D. (2006). Neuroimaging in borderline personality disorder. J. Psychiatr. Res. 40, 419-427.

Segal, H. G., Westen, D., Lohr, N. E., and Silk, K. R. (1992). Assessing object relations and social cognition in borderline personality disorders from stories told to the picture arrangement subtest of the WAIS-R. J. Pers. Disord. 6, 458-470.

Segal, H. G., Westen, D., Lohr, N. E., and Silk, K. R. (1993). Clinical assessment of object relations and social cognition using stories told to the picture arrangement subtest of the WAIS-R. J. Pers. Assess. 61, 58-80.

Sheehan, D. V., Lecrubier, Y., Sheehan, K. H., Amorim, P., Janavs, J., Weiller, E., Hergueta, T., Baker, R., and Dunbar, G. C. (1998). The mini-international neuropsychiatric interview (M.I.N.I.): the development and validation of a structured diagnostic psychiatric interview for DSM-IV and ICD-10. J. Clin. Psychol. 59, 22-33.

Shin, L. M., Wright, C. I., Cannistraro, P. A., Wedig, M. M., McMullin, K., Martis, B., Macklin, M. L., Lasko, N. B., Cavanagh, S. R., Krangel, T. S., Orr, S. P., Pitman, R. K., Whalen, P. J., and Rauch, S. L. (2005). A functional magnetic resonance imaging study of amygdala and medial prefrontal cortex responses to overtly presented fearful faces in posttraumatic stress disorder. Arch. Gen. Psychiatry 62, 273-281.

Silk, K. R., Lee, S., Hill, E. M., and Lohr, N. E. (1995). Borderline personality disorder symptoms and severity of sexual abuse. Am. J. Psychiatry 152, 1059-1064.

Skodol, A. E., Pagano, M. E., Bender, D. S., Shea, M. T., Gunderson, J. G., Yen, S., Stout, R. L., Morey, L. C., Sanislow, C. A., Grilo, C. M., Zanarini, M. C., and McGlashan, T.H. (2005). Stability of functional impairment in patients with schizotypal, borderline, avoidant, or obsessive-compulsive personality disorder over two years. Psychol. Med. 35, 443-451.

Soeteman, D. I., Hakkaart-van Roijen, L., Verheul, R., and Busschbach, J. J. (2008). The economic burden of personality disorders in mental health care. J. Clin. Psychol. 69, 259-265.
Torgersen, S., Czajkowski, N., Jacobson, K., Reichborn-Kjennerud, T., Roysamb, E., Neale, M. C., and Kendler, K. S. (2008). Dimensional representations of DSM-IV cluster B personality disorders in a populationbased sample of Norwegian twins: a multivariate study. Psychol. Med. 38, 1617-1625.

Veen, G., and Arntz, A. (2000) Multidimensional dichotomous thinking characterizes borderline personality disorder. Cognit. Ther. Res. 24, 23-45.

Wagner, A. W., and Linehan, M. M. (1999). Facial expression recognition ability among women with borderline personality disorder: implications for emotion regulation? J. Pers. Disord. 13, 329-344.

Westen, D. (1990). Towards a revised theory of borderline object relations: contributions of empirical research. Int. J. Psychoanal. 71, 661-693.

Westen, D. (1991a). Clinical assessment of object relations using the TAT. J. Pers. Assess. 56, 56-74.

Westen, D. (1991b). Social cognition and object relations. Psychol. Bull. 109, 429-455.

Westen, D., Lohr, N., Silk, K. R., Gold, L., and Kerber, K. (1990a). Object relations and social cognition in borderlines, major depressives, and normals: a thematic apperception test analysis. Psychol. Assess. J. Consult. Clin. Psychol. 2, 355-364.

Westen, D., Ludolph, P., Block, M. J., and Wixom, J. (1990b). Developmental history and object relations in psychiatrically disturbed adolescent girls. Am. J. Psychiatry 147, 1061-1068.

Westen, D., Ludolph, P., Lerner, H., and Ruffins, S. (1990c). Object relations in borderline adolescents. J. Am. Acad. Child Adolesc. Psychiatry 29, 338-348.

Westen, D., Ludolph, P., Silk, K. R., Kellam, A., Gold, L. and Lohr, N. (1990d). "Object relations in borderline adolescents and adults: developmental differences," in Adolescent Psychiatry: Developmental and Clinical Studies, Vol. 17, eds S.C. Feinstein,A.H.Esman, J. G. Looney, G.H. Orvin, J.L. Schimel, A.Z. Schwartzberg, A. D. Sorosky, and M. Sugar (Chicago, IL: University of Chicago Press) 360-384.

Zanarini, M.C. (2000a). Childhood experiences associated with the development of borderline personality disorder. Psychiatr. Clin. North Am. 23, 89-101.

Zanarini, M. C. (2000b). Childhood experiences associated with the development of borderline personality disorder. Psychiatr. Clin. North Am 23, 89-101.

Zanarini, M. C., Frankenburg, F. R., Hennen, J., Reich, D. B., and Silk, K. R. (2005). Psychosocial functioning of borderline patients and axis II comparison subjects followed prospectively for six years. J. Pers. Disord. 19, 19-29.

Zanarini, M. C., Frankenburg, F. R., Hennen, J., Reich, D. B., and Silk, K. R. (2006). Prediction of the 10-year course of borderline personality disorder. Am. J.Psychiatry 163, 827-832.

Zanarini, M. C., Williams, A. A., Lewis, R. E., Reich, R. B., Vera, S. C., Marino, M. F., Levin, A., Yong, L., and Frankenburg, F. R. (1997). Reported pathological childhood experiences associated with the development of borderline personality disorder. Am. J.Psychiatry 154, 1101-1106.

Zanarini, M. C., Yong, L., Frankenburg, F. R., Hennen, J., Reich, D. B., Marino, M. F., and Vujanovic, A. A. (2002). Severity of reported childhood sexual abuse and its relationship to severity of borderline psychopathology and psychosocial impairment among borderline inpatients. J. Nerv. Ment. Dis. 190, 381-387.

Conflict of Interest Statement: The authors declare that the research was conducted in the absence of any commercial or financial relationships that could be construed as a potential conflict of interest.

Received: 30 March 2010; accepted: 16 November 2010; published online: 02 December 2010.

Citation: Preißler S, Dziobek I, Ritter K, Heekeren HR and Roepke S (2010) Social cognition in borderline personality disorder: evidence for disturbed recognition of the emotions, thoughts, and intentions of others. Front. Behav. Neurosci. 4:182. doi: 10.3389/fnbeh.2010.00182

Copyright (c) 2010 Preißler, Dziobek, Ritter, Heekeren and Roepke. This is an open-access article subject to an exclusive license agreement between the authors and the Frontiers Research Foundation, which permits unrestricted use, distribution, and reproduction in any medium, provided the original authors and source are credited. 